\title{
KAJIAN EKONOMI LOKAL MASYARAKAT DI KAWASAN RAWAN BENCANA DESA BUMIAJI KECAMATAN BUMIAJI KOTA BATU
}

\author{
${ }^{1)}$ Muhammad Addin Albariki, ${ }^{2)}$ Moch. Shofwan \\ 1) 2) Program Studi Perencanaan Wilayah dan Kota, Universitas PGRI Adi Buana Surabaya \\ Email : Adinriki17@gmail.com
}

\begin{abstract}
Abstrak
Desa Bumiaji sebagai kawasan permukiman dengan tingkat rawan bencana yang cukup tinggi yaitu banjir dan tanah longsor. Peneliti bertujuan untuk mengidentifikasi karakteristik ekonomi lokal, dan potensi dan permasalahan pengembangan ekonomi lokal masyarakat di Kawasan Rawan Bencana. Metode penelitihan mengunakan deskriptif kualitatif dan kuantitatif dengan SWOT IFAS EFAS. Teknik pengumpulan data dengan cara wawancara mendalam dokumentsi dan survei instansi. Hasil dari penelitian ini adalah 1) Mata pencaharian di Desa Bumiaji didominasi pada sektor jasa dengan jumlah 2.801 jiwa atau 38\% dari total keseluruhan masyarakat Desa Bumiaji. Produksi pertanian Desa Bumiaji cenderung tidak stabil. Jumlah UMKM yang terletak di Desa Bumiaji adalah sebanyak 33 unit. Hasil produksi dipasarkan ke Pasar Batu, Pasar Karangploso, Pasar Pujon dan terkadang ada yang dibawa ke luar kota, antara lain Pasar Gadang, Pasar Dinoyo, Pasar Blimbing, Kediri, Tulungagung dan bahkan ada yang dikirimkan ke luar jawa. Pengembangan UMKM di Desa Bumiaji sudah ditangani secara khusus. Peran dan dukungan kelembagaan penunjang sebagai sarana pengembangan usaha bagi petani seperti kelompok usaha tani, serta peran Lembaga Pemberdayaan Masyarakat Desa (LPMD), dan koperasi seperti KUD. 2) Arahan strategi pengembangan potensi ekonomi lokal Desa Bumiaji berada pada kuadran II, sehingga strategi yang digunakan dalam arahan ini berupa strategi progresif (Streghts-Threats) yang berarti terus memperbesar pertumbuhan serta kemajuan secara maksimal.
\end{abstract}

Kata kunci: Desa Bumiaji, Ekonomi Lokal, Rawan Bencana

\section{Abstract}

Bumiaji Village is a residential area with a high level of disaster prone, namely floods and landslides. The researcher aims to identify the characteristics of the local economy, and the potential and problems of local economic development of communities in Disaster Prone Areas. The research method used is descriptive qualitative and quantitative with SWOT IFAS EFAS. Data collection techniques by means of in-depth interviews, documentation and agency surveys. The results of this study are 1) Livelihoods in Bumiaji Village are dominated by the service sector with a total of 2,801 people or 38\% of the total population of Bumiaji Village. Agricultural production in Bumiaji Village tends to be unstable. The number of MSMEs in Bumiaji Village is 33 units. The products are marketed to Batu Market, Karangploso Market, Pujon Market and sometimes some are taken outside the city, including Gadang Market, Dinoyo Market, Blimbing Market, Kediri, Tulungagung and some are even sent outside Java. The development of MSMEs in Bumiaji Village has been handled specifically. The role and support of supporting institutions as a means of business development for farmers such as farmer business groups, as well as the role of the Village Community Empowerment Institution (LPMD), and cooperatives such as KUD. 2) The strategic direction for the development of the local economic potential of Bumiaji Village is in quadrant II, so the strategy used in this direction is in the form of a progressive strategy (Streghts-Threats) which means continuing to increase growth and progress to the maximum.

Keywords: Bumiaji Village, Local Economy, Disaster Prone 


\section{PENDAhuluaN}

Desa Bumiaji merupakan sebuah Desa yang terlrtak di Kecamatan Bumiaji serta berada disebelah utara Kota Batu. Luas wilayah Desa Bumiaji adalah 478,88 Ha $(9,1$ $\mathrm{km}^{2}$ ) dan terletak pada ketinggian 850 $1.400 \mathrm{~m}$ diatas permukaan laut (dpl). Suhu rata-rata harian berkisar antara $20{ }^{\circ} \mathrm{C}$ sampai dengan $30{ }^{\circ} \mathrm{C}$. Curah hujan rata-rata 220 $\mathrm{mm} / \mathrm{th}$ dengan jumlah bulan hujan 5 bulan pertahun. Desa Bumiaji terbagi menjadi 4 Dusun, yaitu Dusun Banaran terdiri dari 5 Rukun Warga (RW) dan 19 Rukun Tetangga (RT), Dusun Beru terdiri dari 2 RW dan 4 RT, Dusun Binangun terdiri dari $3 \mathrm{RW}$ dan $12 \mathrm{RT}$, Dusun Tlogorejo terdiri dari $2 \mathrm{RW}$ dan $4 \mathrm{RT}$.

Berdasarkan tata guna tanah yang dimanfaatkan oleh penduduk Desa Bumiaji yang sebagian besar adalah lahan pertanian, menunjukkan bahwa masyarakat Desa Bumiaji mayoritas bekerja sebagai petani. Tanaman yang dibudidayakan meliputi tanaman buah (apel, jeruk, jambu) dan tanaman hortikultura (bawang merah, bawang putih, tomat, seledri, brokoli, kol, cabe, kubis, sawi-sawian) dan tanaman pangan (padi, jagung, ketela pohon, ubi jalar), bunga hias dan bunga potong (Mawar, Krisan) dan juga mulai mengembangkan dam membudidayakan tanaman Tebu, rosella, dan tanaman jenis toga.

Selain komoditas pertanian, sebagian penduduk juga bekerja dan mengembangkan sektor industri kecil antara lain pembuatan jenang apel, sari apel dan kripik buah-buahan, dan pembuatan macam-macam kripik lainnya. Selain itu pembuatan mebeler, pembuatan sandal, juga dikembangkan oleh sebagian warga masyarakat Desa Bumiaji. Selain mata pencaharian diatas, penduduk Desa Bumiaji juga berprofesi sebagai guru, TNI, karyawan swasta, tenaga medis, dll. Jumlah penduduk Desa Bumiaji pada tahun 2019 adalah 7.316 jiwa, dengan rincian 3.714 penduduk laki-laki, serta 3.602 penduduk perempuan. Kepadatan penduduk di Desa Bumiaji adalah 763 Jiwa $/ \mathrm{Km}^{2}$. Berdasarkan jenis penggunaan lahan, Desa Bumiaji terbagi sebagai berikut : sawah irigasi teknis $70 \mathrm{Ha}$, sawah irigasi semi teknis $27 \mathrm{Ha}$, tegal / ladang $212 \mathrm{Ha}$, pemukiman 43,2 $\mathrm{Ha}$, pemukiman real estate
1,5 Ha, tanah kas Desa 33,08 Ha, lapangan 2,3 Ha, perkantoran / pemerintahan 1,3 Ha, Jalan 28.6 Ha, sekolah 2,7 Ha.

Ditinjau dari aspek geografis dan geologi wilayah Desa Bumiaji merupakan kawasan rawan bencana longsor. Terdapat tiga zona kawasan rawan bencana tanah longsor di Desa Bumiaji yaitu zona A terdapat klasifikasi tingkat sedang dengan skor akhir 1,8 yang memiliki tingkat kemiringan lereng $>40 \%$, zona $\mathrm{B}$ terdapat tingkat klasifikasi sedang dengan skor akhir 2,2 dan tinggi dengan skor akhir 2,45 yang memiliki tingkat kemringan lereng 15-40 \%, dan zona $\mathrm{C}$ terdapat tingkat klasifikasi rendah dengan skor akhir 1,65 dan sedang dengan skor akhir 2,45 yang memiliki tingkat kemiringan lereng $0-15 \%$.

\section{METODE}

Rancangan dalam penelitian ini menggunakan jenis penelitian deskriptif kuantitatif. Penelitian deskriptif kuantitatif menggunakan pola berpikir deduktif (rasionalempiris atau top-down), yang berusaha memahami suatu fenomena dengan cara menggunakan konsep-konsep yang umum untuk menjelaskan fenomena-fenomena yang bersifat khusus. Pengumpulan data dilakukan melalui pengukuran dengan menggunakan alat yang objektif dan baku serta melibatkan penghitungan angka atau kuantifikasi data. Tujuan dari penelitian kuantitatif adalah untuk menentukan hubungan antar variabel dalam sebuah populasi.

Variabel dan Definisi operasional merupakan suatau pengertian variabel (yang diungkap dalam definisi konsep) tersebut secara operasional secara praktik secara nyata dalam lingkup obyek penelitian/obyek yang diteliti. Definisi operasional akan dijelaskan pada Tabel 1.

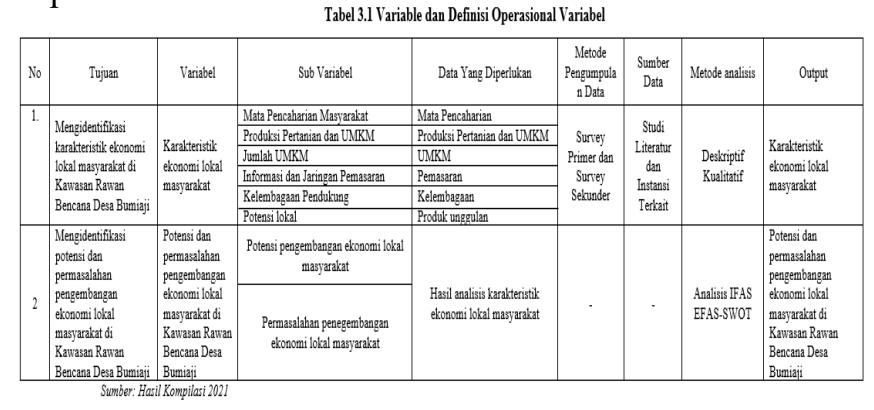


Metode pengumpulan data yang digunakan dalam penelitian ini dibagi menjadi dua tahapan pengumpulan data, yakni pengumpulan data secara primer dan pengumpulan data secara sekunder.

\section{Survei Primer}

Survei primer merupakan kegiatan pengumpulan data yang dilakukan secara langsung dan memiliki tujuan untuk memperkuat keadaan sebenarnya pada lokasi penelitian Sugiyono (2011). Survei primer dilakukan dengan beberapa cara, yaitu:

\section{a. Dokumentasi}

Dokumentasi adalah mengumpulkan data dengan cara mengambil data-data dari catatan, dokumentasi, administrasi yang sesuai dengan masalah yang diteliti. Dalam penelitian ini dokumentasi diperoleh melalui dokumen-dokumen gambaran atau foto kondisi lahan pertanian di lapangan dan hasilnya dispasialkan dalam bentuk peta, foto, atau gambar hasil dari observasi ini dapat berupa data kualitatif dan kuantitatif.

\section{Survei Sekunder}

Survei sekunder adalah kegiatan pengumpulan data secara tidak langsung melalui media perantara. Data sekunder pada umumnya adalah bukti, catatan atau laporan historis yang tersusun dalam arsip yang telah dipublikasikan maupun tidak dipublikasikan. Pengumpulan data sekunder dilakukan dengan cara sebagai berikut:

\section{a. Studi Literatur}

Studi literatur merupakan cara dalam mencari referensi yang lebih relevan dengan suatu permasalahan yang telah ditemukan, referensi tersebut dapat ditemukan dalam berbagai media antara lain, buku, jurnal, artikel, laporan penelitian, laporan kegiatan, dan lain sebagainya. Fungsi dari studi literatur ini untuk memperkuat permasalahan dan sebagai landasan teori dalam melakukan penelitian. Melalui studi literatur ini akan dailakukan studi komparatif mengenai keadaan yang ada dilapangan dengan data dari studi literatur.

\section{HASIL DAN PEMBAHASAN}

Mata Pencaharian Masyarakat

Penelitian dilakukan di Desa Bumiaji untuk mengetahui kareteristik mata pencaharian masyarakat Desa Bumiaji Dilihat dari tata guna tanah yang dimanfaatkan oleh penduduk Desa Bumiaji yang sebagian besar adalah lahan pertanian, menunjukkan bahwa masyarakat Desa Bumiaji mayoritas bekerja sebagai petani. Lebih jelasnya dapat di lihat pada Tabel 2.

Tabel 2. Mata Pencaharian Masyarakat Desa Bumiaji

\begin{tabular}{|c|c|}
\hline Mata Pencaharian & Jumlah (Jiwa) \\
\hline Petani & 1.264 \\
\hline Peternak & 11 \\
\hline Pedagang & 297 \\
\hline Wisaswasta & 224 \\
\hline Jasa & 2.801 \\
\hline Industri & 34 \\
\hline Belum Bekeria & 1.350 \\
\hline Pelajar & 1.168 \\
\hline Lain-Lain & 147 \\
\hline
\end{tabular}

Sumber : Kecamatan Bumiaji Dalam Angka, 2019

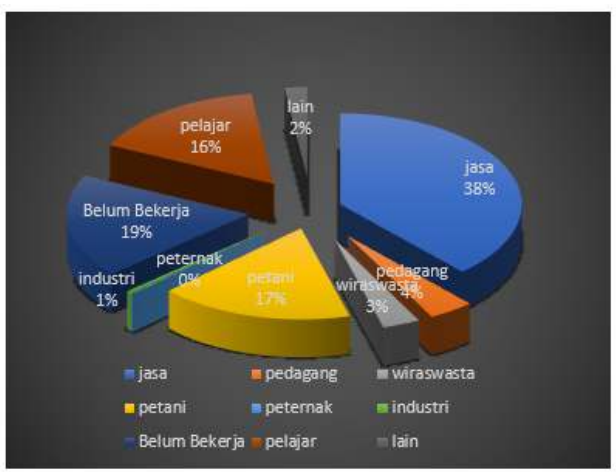

Gambar 1. Persentase Mata

Pencaharian Masyarakat Desa Bumiaji

Berdasarkan hasil persentase pada Gambar 1. mata pencaharian masyarakat Desa Bumiaji Mayoritas masyarakat Desa Bumiaji mempunyai mata pencaharian sebagai jasa 38 $\%$ dengan disusul mata pencaharian sebagai petani $17 \%$ dan belum bekerja sebanyak $19 \%$. dengan ini dapat di katakan mata pencaharian masyarakat Desa Bumiaji yang mendorong ekonomi lokal Desa Bumiaji adalah petani dengan presentase $17 \%$ di bawah mata pecaharian jasa yang $38 \%$.

Dapat di simpulkan bahwa mata pencaharian petani harus dikembangkan karena kegiatan mata pencaharian petani termasuk dalam kegiatan ekonomi lokal Desa Bumiaji. Dengan dikembangkan kualiatas mata pencarihan petani agar menjadikan petani yang berkualitas dan menghasikan 
produk pertanian yang bagus dapat menungkatkan ekonomi lokal masyarakat Desa Bumiaji karena di Desa Bumiaji lahan pertanian sangat besar dan mermiliki berbagai macam tanaman pertanian yang dapat di manfaatkan dan dijadikan produk lokal masyarakat Desa Bumiaji.

\section{Produksi Pertanian dan UMKM}

Berdasarkan tata guna tanah yang dimanfaatkan oleh penduduk Desa Bumiaji yang sebagian besar adalah lahan pertanian, menunjukkan bahwa masyarakat Desa Bumiaji mayoritas bekerja sebagai petani. Tanaman yang dibudidayakan meliputi tanaman buah (apel, jeruk, jambu, dll) dan tanaman hortikultura (bawang merah, bawang putih, tomat, seledri, brokoli, kol, cabe, kubis, sawi-sawian) dan tanaman pangan (padi, jagung, ketela pohon, ubi jalar). Berikutn ini merupakan tabel perkembangan produksi pertanian Desa Bumiaji dari tahun 2017 sampe tahun 2019.

\section{Jumlah UMKM}

Banyaknya wisatawan yang datang ke Kota Wisata Batu sehingga membuat banyaknya potensi pasar yang tumbuh, sehingga menjadi lahan masyarakat setempat untuk melakukan aktivitas ekonomi. Tidak ketinggalan juga Desa Bumiaji yang ikut terdampak oleh kunjungan wisatawan di Kota Batu. Potensi lokal Desa Bumiaji juga mendukung berkembangnya wisata Agro, seperti buah apel yang dapat di jadikan oleh oleh karena Desa Bumiaji merupakan salah satu penghasil Apel yang melimpah sehingga dapat di jadikan berbagai olahan makanan sebagai produk UMKM. UMKM di Desa Bumiaji pun semakin bertumbuh pesat di dukung dengan keistimewaan Kota Batu yang menjadi Kota Wisata, sehingga cukup menjanjikan bagi pelaku usaha yang ada di Desa Bumiaji. Berdasarkan data Potensi Desa Bumiaji tahun 2019, total ada 33 jenis UMKM yang ada di Desa Bumiaji. Berikut ini merupakan daftar UMKM yang ada di Desa Bumiaji.

\section{Informasi dan Jaringan Pemasaran}

Informasi pasar merupakan hal yang sangat penting dalam kegiatan perekonomian saat ini. Informasi pasar ini berperan sebagai kunci yang akan membantu petani dan pelaku usaha dalam menentukan strategi bisnis, menetapkan resiko yang ditanggung, menentukan harga jual, dan memperbesar pangsa pasar. Di Desa Bumiaji, kegiatan pemasaran masih bersifat terbuka, siapapun dapat masuk dan mengambil peran sebagai penjual (pengepul, distributor, dll). Mengingat pemasaran hasil pertanian relatif dekat maka banyak juga penduduk Desa yang berprofesi sebagai pedagang sayur mayur. Mereka memperoleh dagangannya langsung dari petani yang kemudian dipasarkan ke Pasar Batu, Pasar Karangploso, Pasar Pujon dan terkadang ada yang dibawa ke luar kota, antara lain Pasar Gadang, Pasar Dinoyo, Pasar Blimbing, Kediri, Tulungagung dan bahkan ada yang dikirimkan ke luar jawa. Disamping itu ada juga pedagang keliling yang menjual hasil bumi dari Bumiaji langsung ke konsumen di perumahan-perumahan.

\section{Kelembagaan Pendukung}

Pengembangan UMKM di Desa Bumiaji sudah ditangani secara khusus. Peran dan dukungan kelembagaan penunjang sebagai sarana pengembangan usaha bagi petani seperti kelompok usaha tani, serta peran Lembaga Pemberdayaan Masyarakat Desa (LPMD), dan koperasi seperti KUD terbilang cukup bagus dan umumnya sudah berfungsi berfungsi secara maksimal. Tingginya kemampuan dan peran kelembagaan penunjang mengakibatkan petani mampu mengakses sumber pembiayaan, informasi, jaringan pasar dan teknologi. Sehingga para pelaku usaha mampu menjalin hubungan yang baik dengan mitra usaha.

Perkembangan saat ini memperlihatkan banyaknya asosiasi maupun paguyuban petani tumbuh dan berkembang secara mandiri. Desa bumuaji sendiri juga sudah memiliki asosiasi atau paguyuban para petani sebagai lembaga untuk menyediakan fasilitas yang dibutuhkan oleh petani (sarana produksi), serta meningkatkan posisi tawar menawar petani dalam kegiatan ekonomi, sehingga dapat 
mengurangi kesenjangan dan kerugian yang dialami oleh petani. Berdasarkan data dari Dokumen Dinas Pertanian Kota Batu tahun 2019 , terdapat 2 kelompok tani yang saat ini masih aktif di Desa Bumiaji yaitu :

a.Kelompok Tani (Gapoktan) Aji Jaya

Kelompok tani ini dibentuk tahun 2015, dengan luas lahan pertanian mencapai 2.490 $\mathrm{m}^{2}$ dengan telah memiliki sertifikat dengan nomor : 166-LSPO-005-IDN-09-17.

b.Kelompok Tani (Gapoktan) Mitra Arjuna

Kelompok tani ini dibentuk tahun 2016, dengan luas lahan pertanian mencapai 2.700 $\mathrm{m}^{2}$ dengan telah memiliki sertifikat dengan nomor : 168-LSPO-005-IDN-11-16.

\section{Potensi Ekonomi Lokal}

Desa Bumiaji mempunyai beberapa potensi unggulan, terutama produk tanaman tahunan yakni buah-buahan. Berikut ini merupakan perhitungan sektor unggulan yang menjadi potensi ekonomi lokal masyarakat Desa Bumiaji.

Perhitungan LQ =

$$
\begin{array}{ll}
\text { Alpukat } & =\frac{11 / 78}{62,5 / 234,9}=\frac{0,14}{0,38}=0,36 \\
\text { Apel } & =\frac{32 / 78}{54,4 / 134,9}=\frac{0,41}{0,40}=1,02 \\
\text { Mangga } & =\frac{9 / 78}{22 / 134,9}=\frac{0,11}{0,16}=0,68 \\
\text { Jeruk Manis } & =\frac{12 / 78}{28,5 / 134,9}=\frac{0,15}{0,21}=0,71 \\
\text { Jeruk Keprok } & =\frac{7 / 78}{16 / 134,9}=\frac{0,08}{0,11}=0,72 \\
\text { Jambu Biji } & =\frac{3 / 78}{6,5 / 134,9}=\frac{0,03}{0,04}=0,75 \\
\text { Jambu Air } & =\frac{4 / 78}{9,5 / 434,9}=\frac{0,05}{0,07}=0,71
\end{array}
$$

Berdasarkan hasil analisis LQ tersebut, dapat diketahui bahwa potensi unggulan di Desa Bumiaji ialah buah apel dengan nilai LQ sebesar 1,02. artinya, komoditas buah apel menjadi basis atau menjadi sumber pertumbuhan. Komoditas buah apel juga memiliki keunggulan komparatif, hasilnya tidak saja dapat memenuhi kebutuhan di wialyah bersangkutan akan tetapi juga dapat diekspor ke luar wilayah. Hal inilah yang sudah dikembangkan di Desa Bumiaji sebagai salah satu usaha untuk mendongkrak perekonomian masyarakat antara lain adalah usaha pengembangan sektor pariwisata dengan usaha pengembangan wisata petik apel yang lebih dikenal dengan nama Wisata Bukit Apel Desa Bumiaji. Sedangkan untuk mendukung usaha peningkatan hasil usaha di bidang pertanian dan usaha penyelematan lingkungan masing-masing dusun yang ada di Desa Bumiaji dibentuk kelompok tani dan kelompok ternak sesuai dengan usaha masingmasing yang ada di dalam kelompok masyarakat.

\section{KESIMPULAN}

Berdasarakan hasil analisis dan pembahasan maka dapat disimpulkan:

1. Mata pencaharian di Desa Bumiaji didominasi pada sektor jasa dengan jumlah 2.801 jiwa atau 38\% dari total keseluruhan masyarakat Desa Bumiaji. Produksi pertanian Desa Bumiaji cenderung tidak stabil.Jumlah UMKM yang berada di Desa Bumiaji adalah sebanyak 33 unit. Hasil produksi dipasarkan ke Pasar Batu, Pasar Karangploso, Pasar Pujon dan terkadang ada yang dibawa ke luar kota, antara lain Pasar Gadang, Pasar Dinoyo, Pasar Blimbing, Kediri, Tulungagung dan bahkan ada yang dikirimkan ke luar jawa. Pengembangan UMKM di Desa Bumiaji sudah ditangani secara khusus. Peran dan dukungan kelembagaan penunjang sebagai sarana pengembangan usaha bagi petani seperti kelompok usaha tani, serta peran Lembaga Pemberdayaan Masyarakat Desa (LPMD), dan koperasi seperti KUD.

2. Arahan strategi pengembangan potensi ekonomi lokal Desa Bumiaji berada pada kuadran II, sehingga strategi yang digunakan dalam arahan ini berupa strategi progresif (Streghts-Threats) yang berarti terus memperbesar pertumbuhan serta kemajuan secara maksimal, antara lain : 1) 
Menerapkan sistem pertanian terpadu untuk meningkatkan produktivitas pengembangan sektor dan komoditas unggulan berupa sistem tanam polikultur, sistem integrasi tanaman dan ternak, serta hilirisasi pertanian. 2) Meningkatkan manajemen bencana agar mengurangi dampak atau risiko terhadap UMKM atau lahan pertanian yang terletak disekitaran lokasi rawan bencana

\section{UCAPAN TERIMAKASIH}

Ucapan terima kasih kepada Universitas PGRI Adibuana Surabaya yang telah memberikan kesempatan kepada peneliti untuk melakukan penelitian dan terselesaikannya artikel ini.

\section{DAFTAR PUSTAKA}

BPS (Badan Pusat Statistik). Tahun 2018. Kecamatan Bumiaji Dalam Angka

Dhuha, Bayuaji Ginajar, dkk. 2016. Analisis Penetuan Zonasi Risiko Bencana Tanah Longsor Berbasis Sistem Infonmasi Geografi (Studi Kasis; Kabupaten Banjarnegara). Jurnal Geodesi Undip Volume 5 hal $326-335$.

Didik Agus SP. 2005. Bencana Alam, Bencana Teknologi, Racun Dan Polusi Udara; Sebuah Tinlauan Psikologi Lingkungan. Jurnal Buletin Psikologi. Volume 13, No. I,

Esa, Francisca. Dkk.2017. Tingkat Keberlanjutan Pengembangan Desa Wisata Gunungsari Kota Batu. Jurnal Tata Kota dan Daerah Vol.9, No. 1

Ferawati.2018. Studi Pengaruh Erupsi Gunung Sinabung Terhadap Sektor Pertanian Di Kabupaten Karo Sumatera Utara. Jurnal Kapita Selekta Geografi, Volume 1 No.3. Oktober 2018. (Halaman: 55-60)

Paimin. Sukresno. Pramono B, I. (2009). Teknik Mitigasi Banjir dan Tanah Longsor. Bogor: Tropenbos International Indonesia Programme.
Prasetyaningsih Eka Dyah Wahyu,

Widjonarko. 2015. Strategi

Pengembangan Ekonomi Lokal

Berbasis Komoditas Salakdi

Kecamatan Madukara Kabupaten

Banjarnegara,volume 04, No. 04 (2015).

Pranatasari, D, S. Miardini, A. Dan Harjadi, B. (2017). Analisis Kerentanan Tanah Longsor Sebagai Dasar Mitigasi di Kabupaten Banjarnegara. Jurnal Penelitian

Rema, M, Y. Setijawan, A. dan Widodo, W,H,S. (2017). Zonasi Kawasan Berdasarkan Tingkat Risiko Bencana Tanah Longsor di Kota Batu.

Shofwan. Moch. 2018. Mitigasi Bencana Erosi dan Longsor (Kajian Teori dan Teknis). Sidoarjo: Mejatamu

Susanti, Etika Ari, dkk.2014. Pengembangan Ekonomi Lokal Dalam Sektor Pertanian (Studi pada Kecamatan Pagelaran Kabupaten Malang. Jurnal Administrasi Publik (JAP), Vol. 1, No. 4. (Hal 31-40).

Utama, Yusak Senja, dan Bawole, Paulus.2017. Pengaruh Pembangunan Berbasis Masyarakat Terhadap Pengurangan Dampak Kerentanan Bencana Alam Dan Ekonomi Di Pedesaan. Jurnal arsitektur Vol.8, No.3. (Hal 20-31)

UU RI (Undang - Undang Negara Republik Indonesia Nomor 24 Tahun 2007, Tentang Penanggulangan Bencana).

Wiranta, Dayat NS. 2015. Penguatan Peran Pemerintah Daerah dalam Mendorong Pertumbuhan Ekonomi Lokal: Peluang dan Tantangan Masyarakat Ekonomi ASEAN (MEA) 2015. Jurnal Lingkar Widyaiswara. Edisi 2 No. 3, Jul - Sep 2015, p.33 - 50 ISSN: 2355. 